\title{
Abordagem sobre a participação no Governo Lula
}

Paludo, José Roberto

Abordagem sobre a participação no Governo Lula

Administração Pública e Gestão Social, vol. 11, núm. 3, 2019

Universidade Federal de Viçosa, Brasil

Disponível em: http://www.redalyc.org/articulo.oa?id=351559268004

Esta obra está bajo una Licencia Creative Commons Atribución-NoComercial-SinDerivar 3.0 Internacional. 


\section{Abordagem sobre a participação no Governo Lula}

Approach on participation in the Lula Government

Enfoque sobre la participacion em el Gobierno Lula

José Roberto Paludo

Universidade Federal de Santa Catarina, Brasil

Redalyc: http://www.redalyc.org/articulo.oa?

paludoprofessor@gmail.com

$\mathrm{id}=351559268004$

Recepção: 09 Fevereiro 2017

Aprovação: 09 Março 2018

Publicado: 01 Julho 2019

\section{Resumo:}

O tema da participação da população em políticas públicas ganhou espaço na agenda institucional nos anos 1980, despertou grande interesse na academia e, embora se perceba um declínio da sua ação, o Brasil ainda é considerado um "laboratório de experiências" de práticas participativas para o mundo (Cortes \& Silva, 2010). O presente artigo inicia por uma revisão das principais correntes teóricas que abordam o tema da participação em políticas públicas e, em seguida, apresenta os resultados da experiência desse tipo de política na esfera federal, durante o governo Lula (2003-2010), a partir de um balanço publicado pela Secretaria Geral da Presidência da República (SGPR - Brasil, 2011) e do Comunicado de número 132 do Instituto de Pesquisa Econômica Aplicada - IPEA (2012). Tais documentos são analisados à luz do referencial teórico, apontando avanços e desafios futuros.

PalaVras-chave: Participação, Políticas Públicas, Governo Federal.

\section{Abstract:}

The participation of the Brazilian population in public policies gained space in the institutional agenda in the 1980s, aroused great interest in the academy, and although there is a decline in its action, Brazil is still considered a laboratory for participatory practices for the world (Cortes \& Silva, 2010). This article begins with a review of the main theoretical trends that approach the theme of participation in public policies and after that, presents the results of the experience of this type of policy at the federal level, during both Lula's mandates (2003-2006 and 2007-2010), based on a balance sheet published by the General Secretariat of the Presidency of the Republic (SGPR - Brazil, 2011) and IPEA (Institute os Applied Economic Research) Communiqué 132 (2012). These documents are analyzed in the light of the theoretical framework and indicate future advances and challenges.

KEYWORDS: Participation, Public Policy, Federal Government.

\section{RESUMEN:}

La participación de la población brasileña en políticas públicas ganó espacio en la agenda institucional en los años 1980, despertó gran interés en la academia y, aunque se percibe un declive de su acción, Brasil todavía es considerado un ejemplo de "laboratorio de experiencias" para prácticas participativas para el mundo ("Cortes \& Silva, 2010). El presente artículo comienza por una revisión de las principales corrientes teóricas que abordan el tema de la participación en políticas públicas y, a seguir, presenta los resultados de la experiencia de ese tipo de política en la esfera federal, durante los dos mandatos del presidente Lula (2003-2006 y 2007-2010), a partir de un balance publicado por la Secretaría General de la Presidencia de la República (SGPR - Brasil, 2011) y del Comunicado de número 132 del Instituto de Investigación Económica Aplicada - IPEA (2012). Tales documentos son analizados a la luz del referencial teórico, apuntando avances y desafíos futuros.

Palabras clave: Participación, Políticas Públicas, Gobierno Federal.

\section{INTRODUÇÃO}

A partir da década de 1980, a participação social nas políticas públicas se tornou quase consenso em âmbito internacional e, por motivos distintos, têm confluído os pensamentos tanto de esquerda quanto neoliberais (Fonseca, 2011). No Brasil, embora não haja um consenso sobre a interpretação histórica desse processo, 
reconhece-se que o ativismo ou a ação dos movimentos sociais ganhou status institucional na Constituição Federal de 1988 (Fonseca, 2011; Faria \& Ribeiro, 2011; Almeida \& Cunha, 2011; Abers \& Keck, 2008).

Além disso, é importante contextualizar o tema historicamente e também sob o aspecto da agenda de pesquisa no Brasil. Do ponto de vista histórico, o tema da participação no Brasil surge nos anos 1960, "como ideário carregado de uma visão emancipatória das camadas populares" (Lavalle, 2011) e sequer se referia às eleições ou às instituições de governo representativo, estando conectada à teologia da libertação[1], contra a injustiça social e relacionada ao papel da esquerda e sua estratégia basista como alternativa à esfera política. Esse ideário participativo adquiriu novo perfil no contexto da redemocratização e, com a Constituinte, "a participação, outrora popular, tornou-se cidadã" (Lavalle, 2011), os atores engajados passaram a reelaborar seu discurso e o campo dos atores sociais diversificou-se com a multiplicação de organizações não governamentais (ONGs) (Lavalle, 2011).

Nos anos seguintes, a participação adotou os conselhos como instituições participativas (IPs) e, trinta anos depois, estimulou a proliferação de dezenas desses conselhos nas mais diversas áreas, chegando a um total aproximado de 39 mil deles atualmente, segundo o Instituto de Pesquisa Econômica Aplicada (IPEA) de 2005 (FONSECA, 2011).

Por isso, alguns autores veem a participação com otimismo e afirmam que "o Brasil constituiu-se, ao longo das últimas décadas, como um dos principais 'laboratórios' de experiências e de análise da participação social na gestão pública" (Cortes \& Silva, 2010), enquanto outros depositam menos expectativas, considerando que as IPs são "de caráter incremental no Brasil, o que significa que, na verdade, não se deve esperar, a partir de sua mera presença e atuação, transformações dramáticas nos resultados observados” (Wampler, 2011a).

Do ponto de vista da agenda de pesquisa sobre o tema, Lubambo e Miranda (2007) descrevem o estado da arte da temática e pode-se considerar que ela já passou por duas fases. A primeira, também chamada de fase de repertórios (Fonseca, 2011) ou com perspectiva laudatória (Silva, 2011), tratou de descrever os casos, fazer estudos comparativos, ressaltando a importância da participação e suas vantagens e "muitas vezes em resposta ao 'dilema da ação coletiva' proposto por Olson (1999), boa parte da literatura concentra seus esforços em tentar elucidar as razões que levam os indivíduos a participarem politicamente" (Cortes, 2011). Porém, a segunda fase foi marcada pelos focos na efetividade e nos resultados das experiências participativas (Fonseca, 2011; Wampler, 2011b) e nos fatores que influenciam ambos.

Esses fatores podem ser divididos em três conjuntos: o primeiro conjunto, considerado "neoinstitucinalista", defende a tese de que o desenho institucional é fator determinante para os resultados da participação, tanto no que diz respeito à seleção dos participantes, à agenda de debates, ao funcionamento das instituições participativas e à quantidade de recursos disponível, definidos previamente através dos respectivos regulamentos (Faria \& Ribeiro, 2011), ou seja, "como instituições produzem resultados" (Borba, 2011); o segundo conjunto atribui os resultados como consequência do funcionamento das IPs (assimetria de informações, legitimidade do processo, quem participa e como participam, ciclos ou etapas da participação, esferas de governo ou níveis de participação, a forma como ocorre o funcionamento e como são observadas as regras), ou seja, o foco é interno às instituições participativas (Silva, 2011; Cortes \& Silva, 2011; Tatagiba, 2011; Luchmann, 2007); e finalmente, o terceiro conjunto defende o contexto como causa dos resultados da participação (Souza, 2011; Silva, 2011; Campos, 2011) e dentre as questóes contextuais consideram que cada experiência tem suas especificidades históricas, políticas, sociais e culturais, como concluem Faria e Ribeiro (2011) “a variável política, especificamente, ganha destaque não só na determinação do sucesso dessas instituições, mas também na determinação do próprio desenho institucional que elas assumem"; e ainda, Tatagiba (2011) concordando com Dagnino (2006), acrescenta: "a identificação do projeto político dos governos como uma das variáveis relevantes na avaliação da qualidade da participação e seus resultados" (Tatagiba, 2011).

Diante desse histórico percorrido pelo tema da participação brasileira, tanto do ponto de vista da prática das políticas públicas como do ponto de vista da sua agenda de pesquisa, pode-se afirmar que os desafios 
atuais apontam para "a complexidade da democracia brasileira, das suas instituições e das possíveis interações entre elas que demandam estudos, busquem captar o seu caráter complexo e possam verificar a qualidade dos processos e dos resultados que são produzidos" (Cunha, Almeida, Faria \& Ribeiro, 2011). Assim, estamos numa "terceira fase" (Almeida \& Cunha, 2011), em que a capacidade das IPs em produzir decisão democrática não é dada como garantida, "mas depende da interação e combinação de algumas variáveis e contextos sociopolíticos" (Almeida \& Cunha, 2011). Portanto, "o futuro da democracia deliberativa está diretamente relacionado com a capacidade da teoria e empiria interagirem e influenciarem-se mutuamente, de modo a produzirem um conhecimento permanentemente aberto à crítica e à revisão" (Almeida \& Cunha, 2011).

Aqui é que se insere esse artigo, ou seja, problematizar a complexidade e a qualidade da democracia participativa na esfera federal, tomando como recorte temporal o período do governo Lula (de 2003 a 2010), a partir de duas fontes básicas: o relatório de prestação de contas da Secretaria Geral da Presidência da República (SGPR) - "Democracia Participativa: nova relação do Estado com a sociedade” (Brasil, 2011); e o Comunicado 132 do Instituto de Pesquisa Econômica Aplicada (IPEA) "Participação social como método de governo: um mapeamento das 'interfaces socioestatais' nos programas federais” (IPEA, 2012).

Para tanto, o presente artigo divide-se em quatro partes. A primeira parte, já apresentada acima, contextualiza o debate da democracia participativa brasileira na agenda política e na agenda de pesquisa sobre o tema. Na segunda parte, será feita uma abordagem teórica sobre o tema da participação e o tema da democracia: participativa, deliberativa e associativa. Na terceira parte, será apresentada uma síntese dos dois documentos oficiais que servirão de fonte de informações empíricas para essa análise. Por fim, na quarta parte, seguirá uma análise do tema apontando algumas conclusões, lacunas e desafios.

\section{ClassificaÇão dos modelos de democracia}

Se por um lado foi importante resgatar o histórico das experiências e da agenda de pesquisa sobre a participação, é também necessária uma abordagem sobre a classificação dos modelos de democracia. Aqui, toma-se como base um artigo de Lüchmann (2011) intitulado "Modelos contemporâneos de democracia e o papel das associações". Nesse artigo, a autora toma como ponto de partida os problemas e limites da democracia representativa eleitoral, que é a principal razão para estimular o debate sobre novos modelos de democracia, e classifica-os em democracia participativa, democracia associativa e democracia deliberativa.

Segundo Lüchmann (2011), a democracia participativa é inspirada em Rousseau, baseada nos ideais de autogoverno e soberania popular, através da participação direta dos cidadãos nos processos de discussão e de decisão política. Segundo Macpherson (1978), a ideia de democracia participativa surgiu com o movimento estudantil nos anos 1960 e depois com a classe trabalhadora nos anos 1960 e 1970 como algo mais amplo que um método político, ou seja, um tipo de sociedade, de relação recíproca entre as pessoas.

Diante dessa concepção, aponta-se, por um lado, perspectivas críticas, como por exemplo, Fung (2003), que alerta sobre o risco do poder do Estado sobre a sociedade ou da feudalização do estado administrativo, e Warren (2008), que questiona a qualidade da participação e, por outro lado, perspectivas positivas, como a de Barber (1984) e Pateman (1992), que consideram a participação como pedagógica e educativa, em que a participação ativa cria um círculo virtuoso de mudança da consciência política e redução das desigualdades.

Por fim, os teóricos da democracia participativa consideram-na como complementar à democracia representativa e não como alternativa ou contraposição.

De acordo com Lüchmann (2011), a principal diferença entre a democracia participativa e a democracia associativa é apontada por Elstub (2008), em que a participação individual é substituída pelas associações e o ideal de autogoverno é preenchido pelos grupos e associações secundárias.

A democracia representativa apresenta debilidades frente a complexidade e pluralidade dos problemas e demandas sociais, demonstrando-se excludente para grupos sociais historicamente oprimidos e/ou 
subordinados, seja pelo recorte de classe, de gênero, de etnia, de idade, entre outros. Diante disso, aponta-se para a importância das associações, conforme Elstub (2008).

Numa outra perspectiva, Hirst (2001) analisa as mudanças sofridas pelos Estados, principalmente a partir das privatizações, e a atenuação da fronteira entre o público e o privado, portanto, "a democracia associativa é a única doutrina capaz de lidar com os problemas da accountability democrática em uma sociedade culturalmente diversificada" (Hirst, 2001, p.21, in Lüchmann, 2011). Por fim, Hirst (2001), defende a ideia da descentralização por meio de agências de controle.

Contudo, aqui também surgem visões críticas em relação à democracia associativa, como apontam Cohen e Rogers (1995), ressaltando os riscos de faccionismo e balcanização de interesses no interior do Estado. Para esses autores, as associações são artefatos, ou seja, dependem das estruturas econômicas, políticas e institucionais em que estão inseridas e podem variar de acordo com a maior ou menor centralidade de governos, de informações disponíveis, de oportunidades e de incentivos. Assim, o Estado tem papel ativo sobre as associações (Cohen \& Rogers, 1995, in Lüchmann, 2011). Ao mesmo tempo, esses autores indicam pelo menos quatro vantagens na democracia associativa: maior proximidade com os problemas, equalização da representação, uma tradição participacionista que desenvolve virtudes cívicas e a conformação de uma governança alternativa com funções quase-públicas, gerando mais eficiência que uma performance estatal.

Young (1995) também observa a necessidade de distinguir entre associações (formalmente organizadas, a exemplo de clubes, partidos, igrejas, sindicatos, etc.) e grupos sociais pelo recorte de gênero, etnia, orientação sexual, etc. Estes são menos artefatuais, ou mais naturais que os anteriores.

Por fim, sobre o conceito da democracia deliberativa, Lüchmann (2011) traz presente outro conjunto de autores, a começar por Thompson (2008), que define que o núcleo da democracia deliberativa (DD) está na razão, nos argumentos adequados voltados para os formadores de opinião, defende a extensão dos fóruns deliberativos e aponta uma diferenciação no locus e nos atores deliberativos. Habermas (1997; 2005) aponta para processos deliberativos caracterizados pela troca de opiniões e discursos racionais entre iguais, sem manipulação ou repressão, e diferencia a esfera pública formal (representação eleitoral e agências estatais) e informal (grupos, associações e organizações, mais próximas do mundo da vida).

Cohen (1999) critica Habermas por deslocar o foco da participação da sociedade civil para a esfera informal e, ao mesmo tempo, indica três princípios da DD: inclusão deliberativa/pluralismo; promoção do bem comum; direitos iguais de participação, de voto, de associação, de expressão, de ser eleito. A mesma autora aponta os movimentos sociais como atores centrais, reforçados por Dryzek e Niemeyer (2008), que destacam a importância desses atores e do discurso contestatório para o aprofundamento da democracia e da mudança da cultura política. Por exemplo, no campo ético comportamental (feminista, ambientalista, etc.) geram legitimidade, mas correm riscos de absorção e cooptação.

Nesse tema, Lüchmann (2011) referencia também Young (2003), que destaca a importância de romper o ciclo de desigualdades e exclusão, aponta para a ampliação do leque de possibilidades e formas de comunicação, defende um modelo descentrado de sociedade, em que a esfera pública torna-se uma ferramenta de oposição, publicização e de controle do poder, propondo ainda um papel mais ativo das associações na execução de políticas públicas e alertando para os riscos de controle, perda de autonomia e capacidade crítica.

Young (2001) faz outro tipo de distinção, traçando um diálogo entre os que defendem a democracia deliberativa e os ativistas. Os primeiros baseiam-se na importância dos argumentos que chegam em acordos satisfatórios para todos, enquanto os segundos defendem que as desigualdades estruturais influenciam nos procedimentos e nos resultados, portanto, boicotam os processos. Assim, os ativistas são acusados de niilistas, irracionais e de acabarem por beneficiar grupos de interesses através de suas ações. Estes respondem, acusando os deliberacionistas de ingênuos que legitimam as desigualdades estruturais e de informações, nas quais quem está no poder controla a pauta e os mecanismos de decisão. Os deliberacionistas concordam que é necessário haver inclusão e maior publicidade e que isso poderá evoluir com a prática da participação, em vez retirarse por imediatismo (Young, 2011). 
Por fim, a autora defende que ambos os posicionamentos são importantes e é necessário interagir com eles tanto na teoria quanto na prática e, desse modo, propõe uma teoria democrática crítica, um engajamento discursivo, do qual as manifestações de rua também fazem parte, e uma atuação conjunta dos dois repertórios, ou seja, da participação deliberativa e do ativismo, de forma combinada, e não excludente (Young, 2001).

Diante da apresentação feita até aqui, com qual modelo de participação pode-se identificar a experiência brasileira no recorte de tempo proposto? Qual a importância dessas experiências participativas diante de um contexto mais amplo de globalização? Quais os mecanismos característicos dessa experiência e quais os seus resultados? Quais os desafios futuros que se pode apontar diante dessa síntese? Essas são algumas questões para as quais serão propostas respostas ao final deste trabalho.

\section{A experiênCia Participativa no Brasil durante o governo Lula}

Conforme apresentado na introdução deste artigo, essa parte do trabalho tem como base dois documentos. O primeiro trata de um balanço da democracia participativa no período de 2003 até 2010, feito pela Secretaria Geral da Presidência da República - SGPR (Brasil, 2011) e o segundo, de um Comunicado de número 132 do IPEA (IPEA, 2012).

A SGPR recebeu a atribuição de promover a participação social no Governo Federal através da Medida Provisória 103, em $1^{\circ}$ de janeiro de 2003, que posteriormente foi convertida em Lei 10.683, de 28 de maio de 2003, em cujo artigo $3^{\circ}$ consta: "especialmente no relacionamento e articulação com as entidades da sociedade civil e na criação e implementação de instrumentos de consulta e participação popular de interesse do Poder Executivo na elaboração da agenda futura da Presidência da República" (Brasil, 2011).

No documento da SGPR não há uma preocupação com a definição dos termos, simplesmente usa-se a expressão "participação social nas políticas públicas" como um "novo método de governar" (Brasil, 2011). Já em relação ao desenho institucional, o qual o documento chama de "espaços ou mecanismos de participação social”, afirma-se que se consolidou um "Sistema Nacional de Democracia Participativa” (SNDP) composto por conselhos, conferências, mesas de diálogo, ouvidoria pública, programa de formação de conselheiros, participação social através dos Objetivos de Desenvolvimento do Milênio (ODMs) e participação social através de diálogos internacionais que dizem respeito à integração no Mercosul, cooperação internacional e Comunidades de Países de Língua Portuguesa - CPLP (Brasil, 2011).

Ao final, o documento demonstra como a participação social produziu uma reconfiguração do Estado, com a criação de novos Ministérios e Secretarias Especiais, em resposta às demandas apresentadas através desse processo participativo.

O balanço descritivo dos resultados desse conjunto de mecanismos participativos inicia-se pelas ações com participação direta da SGPR em diálogo com a sociedade:

- no período de oito anos contabilizou-se aproximadamente 3.500 encontros, reuniões ou atividades com entidades e personalidades da sociedade civil;

- a Política Nacional Permanente de Valorização do Salário Mínimo foi resultado da mesa de negociação entre o Governo Federal e as centrais sindicais;

- houve diálogo e parceria com as organizações sociais do campo, nas manifestações dos movimentos Grito da Terra, Marcha das Margaridas, Jornada pela Água e Em Defesa da Vida e no Fórum em Defesa da Reforma Agrária;

- na elaboração de programas estratégicos como o Programa de Aceleração do Crescimento (PAC) e Minha Casa Minha Vida foram ouvidos tanto entidades empresariais e sindicais como organizações não governamentais;

- alguns setores historicamente excluídos do diálogo político foram recebidos pela primeira vez por um chefe de Estado: os hansenianos, Associação Brasileira de ONGs (ABONG), pessoas com deficiências, 
catadores de materiais recicláveis e integrantes da luta antimanicomial, oportunidade em que surgiram encaminhamentos para atender as demandas apresentadas;

O primeiro mecanismo de participação, dentro do SNDP, são os conselhos: Em 2010 existiam 34 conselhos nacionais, houve a continuidade daqueles que tinham funcionamento (7), alguns foram reformulados (11) e outros dezesseis novos conselhos foram criados (ver tabela anexa).

Outro mecanismo importante é o das conferências nacionais que ocorreram no mesmo período. Foram 74 conferências em diferentes temas, sendo que algumas realizaram mais de uma conferência nesse período: arranjos produtivos locais (4); comunidades brasileiras no exterior (3); cidades (4); aprendizagem profissional (1); aquicultura e pesca (3); assistência social (4); ciência, tecnologia e inovação (2); ciência, tecnologia e inovação em saúde (1); comunicação (1) cultura (2); defesa civil e assistência humanitária (1); desenvolvimento rural sustentável (1); direitos humanos (4); economia solidária (2); educação (1); educação básica (1); educação escolar indígena (1); educação profissional e tecnológica (1); gays, lésbicas, bissexuais, travestis e transexuais (1); gestão do trabalho e da educação na saúde (1); juventude (1); medicamento e assistência farmacêutica (1); promoção da igualdade racial (2); mulheres (2); recursos humanos da administração pública federal (1); saúde (2); saúde ambiental (1); saúde bucal (1); saúde do trabalhador (1); saúde indígena (1); saúde mental (1); segurança alimentar e nutricional (2); segurança pública (1); meio ambiente (3); esporte (3); direitos da criança e do adolescente (4); direito da pessoa com deficiência (2); direitos da pessoa idosa (2); povos indígenas (1); infanto-juvenil pelo meio ambiente (3) (Brasil, 2011).

Desse número de conferências, muitas delas foram realizadas pela primeira vez e também há diferenças que podem ser ressaltadas em relação à periodicidade, às etapas nas três esferas de poder ou apenas no âmbito nacional, à metodologia de construção (com ou sem documento base), à iniciativa para a convocação motivada pela sociedade ou apenas por interesse do governo e, finalmente, ao formato dos documentos finais aprovados e suas consequências[2].

O terceiro mecanismo de participação definido no SNDP é chamado de "mesas de diálogo" com as Centrais Sindicais que, além do salário mínimo, estabeleceu acordos sobre tabela de imposto de renda e crédito consignado. Com entidades do campo foi negociado crédito agrícola, Programa de Fortalecimento da Agricultura Familiar (PRONAF) Mulheres, assistência técnica, garantia de preços e Programa de Aquisição de Alimentos (PAA); com o Movimento de Atingidos por Barragens (MAB) e uma mesa tripartite sobre as Condições de Trabalho na Cana-de-Açúcar. Na educação debateu-se a Reforma Universitária, Fundo de Manutenção e Desenvolvimento da Educação Básica (FUNDEB), Programa Universidade para Todos (ProUni) e Planos de Reestruturação e Expansão das Universidades Federais (Reuni). Houve uma mesa de negociação permanente com os servidores públicos federais que produziu 70 acordos coletivos, aprovação de 46 Medidas Provisórias e 27 Projetos de Lei que beneficiaram 1,3 milhão de servidores. Por fim, houve também um diálogo pela reforma da Lei do Cooperativismo.

O quarto mecanismo citado diz respeito às ouvidorias públicas, que através da manifestação individual permitem "buscar informações, avaliar, criticar e melhorar os serviços e políticas públicas" (Brasil, 2011). Numericamente, passou-se de 40 Ouvidorias no ano de 2002 para 165 em 2010, que atenderam as manifestações de três milhões de brasileiros, além da realização de eventos sob a coordenação da Controladoria Geral da União (CGU), com destaque para o Fórum das Américas de Ouvidorias, Defensores Del Pueblo e Ombudsman, em Salvador (BA), no ano de 2010.

O quinto mecanismo, o programa de formação de conselheiros, foi resultado de uma parceria com a Universidade Federal de Minas Gerais (UFMG) e a Escola Nacional de Administração Pública (Enap), que promoveram um curso de pós-graduação em Democracia Participativa, República e Movimentos Sociais, dezessete cursos de curta duração e um ciclo de debates e edição de livros.

Em 2003, foi criado um grupo de trabalho para o acompanhamento dos ODMs que elaborou quatro relatórios nacionais (nos anos de 2004, 2005, 2007 e 2010), criou a campanha "Nós Podemos - 8 Jeitos 
de Mudar o Mundo" e o Prêmio ODMs Brasil (2005, 2007/08, 2009/10), nos quais foram inscritos 3.500 projetos e premiados 67.

Quanto à participação social e ao diálogo internacional, destaca-se o lançamento da Ação Global Contra a Fome e a Pobreza (2004) e a participação de setores sociais em fóruns para discutir mecanismos inovadores de financiamento ao desenvolvimento, a criação do Instituto Social do Mercosul (ISM) em 2007 e a criação da Universidade Federal de Integração Latino-Americana (UNILA) em 2010, além de cooperação técnica e transferência de tecnologias sociais na relação com Haiti, organizações sociais africanas, Foro de Diálogo Social Noruega-Brasil e Foro da Sociedade Civil da Comunidade dos Países de Língua Portuguesa (CPLP).

No que diz respeito à reconfiguração do Estado como resultante do processo participativo, destacase a criação do Ministério de Desenvolvimento Social (MDS), que em 2010 chega a operar uma cifra correspondente a 9,1\% do PIB em "programas federais de transferência de renda" (Brasil, 2011). O Ministério das Cidades também foi resultado de reivindicações históricas do movimento pela reforma urbana, assim como o Ministério da Pesca e as secretarias de Direitos Humanos, Políticas para as Mulheres, Promoção da Igualdade Racial, Juventude e Subsecretaria de Promoção dos Direitos das Pessoas com Deficiência (SNPD).

Por fim, a SGPR provocou também um processo participativo na elaboração do Plano Plurianual (PPA) de 2004-2007 e de 2008-2011. No primeiro, foram envolvidas 2.170 entidades de trabalhadores, igrejas, empresários, juventude, defesa do meio ambiente e dos consumidores, instituições culturais e organizações étnicas e de gênero. No segundo, "foi promovido um debate no âmbito dos conselhos e comitês" (Brasil, 2011).

O Comunicado ${ }^{\circ} 132$ do IPEA (2012) inicia apresentando seu conceito de "participação social como método de gestão" no período de 2002 a 2010, dando continuidade aos conselhos e conferências e criando novas formas de participação: consultas públicas, mesas de negociação e ouvidorias. Esses mecanismos têm por objetivo promover a inclusão, a responsabilidade e accountability, a eficiência e eficácia nas políticas públicas, atingindo uma diversidade de áreas, formas e tipos de políticas e de interfaces.

O documento inicia a análise sobre a incidência geral das interfaces socioestatais, no período de 2002 a 2010, afirmando que:

Foi possível perceber pelo menos três importantes fatores nessa linha: i) uma variação positiva no volume de programas com interfaces socioestatais; ii) um processo de diversificação de órgãos que passaram a adotar estes mecanismos em seus respectivos programas ao longo dos anos; e, por fim, iii) um incremento do número médio de interfaces socioestatais nos programas de órgãos que já adotavam estes mecanismos no primeiro ano considerado (IPEA, 2005 - p. 4).

Em 2002, 81\% dos programas possuíam interfaces socioestatais, chegando a 92,1\% em 2010. Da mesma forma, 60,4\% dos órgãos federais tinham interfaces socioestatais em 2002 e passaram para 89,3\% em 2010. No que diz respeito ao número médio de interfaces socioestatais dos programas por cada órgão em 2002, $11,5 \%$ tinham até $25 \%$ de programas com esse tipo de interface e, em 2010, todos os órgãos tinham pelo menos 25\% de programas com interfaces. "Em 2002, 11,5\% dos órgãos tinham mais de 75\% dos seus programas com interfaces socioestatais, percentual que sobe para 75,4\% em 2010" (IPEA, 2012), ou seja, intensificaram-se as interfaces socioestatais dos programas dentro de cada órgão.

Quanto ao tipo de interface, o IPEA o divide em dois grupos: coletivizados (corte vertical, com maior inclusão e periodicidade, por exemplo; conselhos setoriais; conferências; audiência pública e consulta pública); e não coletivizados (corte horizontal, menor inclusão e sem periodicidade, por exemplo; reuniões com grupos de interesse; ouvidoria e outros). No período analisado, o tipo coletivizado passou de $26,6 \%$ para 41,6\%. Com base numa análise qui-quadrado, para observar o grau de significância dos tipos de interface, o IPEA conclui que:

Ao longo dos anos, os percentuais tendem a uma maior homogeneização, isto é, a uma maior semelhança, sugerindo que deixa de haver concentração em determinados tipos de interface e passa a haver uma adoção tendente ao equilíbrio entre os diversos tipos de mecanismos (IPEA, 2012). 
Portanto, dentre as categorias organizadas pelo IPEA, não há um tipo de interface predominante, pelo contrário, recorre-se a todos os tipos proporcionalmente.

Outro aspecto qualitativo da participação, analisado no Comunicado no 132 do IPEA (2012), trata das categorias temáticas ou padrões das interfaces. Nesse sentido, o estudo conclui que $35 \%$ das interfaces ocorrem em relação à categoria temática de proteção social, $32 \%$ na categoria de infraestrutura, 16\% na categoria de desenvolvimento econômico e o mesmo percentual nas questões ambientais. No cruzamento entre as categorias e os tipos de participação, tem-se que, na categoria de proteção social prevalecem os tipos de participação através de conselhos e conferências; na infraestrutura prevalecem as audiências públicas e consultas populares; na categoria ambiental, as reuniões e consultas públicas; e no desenvolvimento econômico prevalecem as conferências e outras formas de participação (IPEA, 2012).

Enfim, outra inferência analisada trata de observar o caráter dos programas: finalísticos ou de apoio. Com caráter finalístico, os mecanismos de participação são mais frequentes/periódicos, do tipo coletivizado e trata de temas ligados à proteção social. Enquanto isso, o caráter de apoio é mais pontual, de tipo não coletivizado, e ocorre nos temas ligados ao desenvolvimento econômico e infraestrutura.

Assim, o Comunicado no 132 do IPEA (2012) conclui que, no período de 2002 a 2010, aumentou o número de mecanismos participativos, aumentou a associação entre os temas, os tipos de interface e o caráter dos programas, constituindo um padrão de tipo coletivizado/finalístico e não coletivizado/apoio (IPEA, 2012).

\section{ANALISANDo A PARTICIPAÇÃo NO GOVERNo Lula}

Apresenta-se aqui uma proposta metodológica baseada na síntese do debate sobre os fatores que influenciam a participação nas políticas públicas. Nesse sentido, divide-se em três conjuntos de fatores: desenho institucional, funcionamento das IPs e contexto. Outros dois textos metodológicos ajudarão a apontar critérios de análise, ou seja, através do conceito de Estrutura de Oportunidade Política - EOP (Cortes \& Silva, 2010) e da metodologia para analisar as conferências, proposta por Souza (2010).

Começando pela análise dos aspectos relacionados ao contexto, pode-se afirmar que é possível reunir três critérios já apresentados anteriormente: o histórico da participação no Brasil, o projeto político do governo que estava assumindo o poder no início do período em análise e a vontade política do governante. Observa-se que, historicamente, como afirma Tatagiba (2011), "os movimentos sociais apostaram na luta 'por dentro do Estado’ como estratégia de transformação social e o próprio surgimento do Partido dos Trabalhadores (PT) se insere no âmbito dessa aposta”. Com a eleição do Presidente Luiz Inácio Lula da Silva, o PT chegou ao Governo Federal, depois de uma trajetória de experiências de participação direta nos governos locais, através do modelo de Orçamento Participativo, portanto, há uma identidade programática desse governo com a proposta participativa.

Do ponto de vista da vontade política, houve a iniciativa de atribuir à SGPR, no primeiro dia de governo, a tarefa de coordenar a interlocução do governo com a sociedade civil (Brasil, 2011), demonstrando que houve preocupação com o tema da participação.

Em relação ao capital social, mesmo considerando que o "Brasil é um laboratório de participação" (Cortes \& Silva, 2010), pode-se perguntar até que ponto as experiências participativas, que ocorreram nesse período, contribuíram para elevar o nível de engajamento ou produzir mudanças significativas na cultura política brasileira?

Quanto aos múltiplos centros de poder (Cortes e Silva, 2010), pode-se observar que, no âmbito internacional, buscou-se inserir a questão da participação da sociedade civil em temas como o Mercosul, a CPLP e os debates sobre a cooperação internacional e a erradicação da pobreza. Porém, no âmbito interno, o foco foi na relação direta entre o Poder Executivo e as organizações da sociedade civil. Talvez nas conferências 
possa aparecer um leque de atores um pouco mais amplo, mas não em relação a outros centros de poderes, como o próprio Parlamento, a mídia, o Poder Judiciário, os partidos políticos, dentre outros.

Um dos fatores mais complexos no âmbito da análise do contexto são as desigualdades estruturais, dentre elas, as distâncias regionais, o custo da participação, a assimetria de informações e até mesmo o controle da agenda e dos resultados, de forma vertical e horizontal. Esse fator apresenta um grau de complexidade difícil de analisar aqui, mas é importante ressaltá-lo como desafio a ser investigado. Chama a atenção o diálogo do governo com manifestações ativistas, como o Grito da Terra, a Marcha das Margaridas, dentre outras. Isso trata daquilo que Young (2001) aponta como necessário: Não desconsiderar o "grito das ruas" como uma forma de participação.

Quanto ao desenho institucional, é importante ressaltar que cada uma das fontes estabeleceu critérios diferentes ao considerar os mecanismos de participação e também que há diversidade nas formas de participação dentre os diferentes tipos e as diferentes IPs de mesmo tipo.

Assim, a SGPR propõe um desenho institucional chamado de SNDP, composto por vários mecanismos: conselhos, conferências, mesas de diálogo, ouvidorias, formação de conselheiros e participação nos ODMs e nos diálogos internacionais (Brasil, 2011). Já o IPEA (2012) considera apenas cinco mecanismos: conselhos, conferências, consultas públicas, mesas de negociação e ouvidoria.

Tratando-se de outro aspecto de diferenciação em relação ao desenho institucional, a análise do IPEA (2012) aponta o critério de tipologia, diferenciando entre tipos coletivizados e não coletivizados, a partir do corte vertical ou horizontal e de uma maior ou menor inclusão e periodicidade. Segundo essa análise, os conselhos e as conferências são formas de participação que se encaixam no tipo coletivizado. Porém, há muita diferença entre ambas e, mais ainda, entre os diferentes conselhos e as diferentes conferências, ou seja, há uma grande pluralidade nas formas e mecanismos de participação, que requer aprofundar avaliações diferentes para cada mecanismo.

Em relação às pautas, geralmente são definidas pelo governo, mas percebe-se que há sintonia com as demandas da sociedade civil, basta observar a lista das conferências nacionais ocorridas no período de 2003 a 2010. Além disso, percebe-se a presença de novos atores até então excluídos do processo político, como por exemplo, os movimentos em favor da diversidade sexual (movimentos LGBTT), étnicos, de gênero e outros. Portanto, houve uma ampliação quantitativa e qualitativa da participação social no Brasil nesse período.

Nos aspectos relativos ao funcionamento dos processos deliberativos e endógenos das instituições participativas, o mais importante também é levantar hipóteses. Iniciando pela legitimidade dos processos participativos e dos próprios participantes (quem participa e como participa), esses fatores precisam ser investigado mais profundamente. Percebe-se que no documento da SGPR, muitos depoimentos de lideranças das grandes entidades nacionais apoiam e legitimam os processos participativos, porém, não se pode ignorar que se trata de um documento oficial, que não tem por objetivo problematizar, mas sim fazer a propaganda dessas ações.

Porém, pode-se levantar hipóteses relativas às consequências dessa participação, como por exemplo: $\mathrm{O}$ engajamento de novos atores e a pluralidade da participação reduziram conflitos? Parece que é possível observar uma redução de conflitos entre governo e sociedade civil e daí, levanta-se outras hipóteses: Houve cooptação dessas entidades por parte do governo ou o governo atendeu suas demandas? Ou ambas? Enfim, mais um questionamento possível de se investigar é: até que ponto as organizações da sociedade civil ou seus líderes engajados diretamente nas instituições participativas, especialmente os conselhos, perderam identidade nas suas bases?

Portanto, mais do que respostas, esse diálogo entre agenda política e agenda de pesquisa também serviu para levantar hipóteses e questionamentos a serem aprofundados. 


\section{CONSIDERAÇÕES}

É possível apontar em qual modelo de participação pode-se identificar a experiência brasileira? Qual a importância dessas experiências participativas diante de um contexto mais amplo de globalização? Quais os mecanismos característicos dessa experiência e quais os seus resultados? Quais os desafios futuros que se pode apontar diante dessa síntese?

O que se pode afirmar é que não se pode caracterizar a experiência brasileira no âmbito nacional como um modelo de participação direta ou de democracia participativa. Nos documentos empíricos analisados, o balanço da SGPR usa duas nomenclaturas, citando o sistema nacional de democracia participativa e os mecanismos de participação social (Brasil, 2011), enquanto o IPEA usa o conceito de "participação social como método de governo" (IPEA, 2012). Diante das três propostas sugeridas por Lüchmann (2011), democracia participativa, democracia associativa e democracia deliberativa, e apesar da pluralidade de desenhos institucionais e de práticas participativas, acredita-se que a experiência brasileira se aproxima mais do conceito de participação associativa.

Ainda que esse aspecto tenha sido destacado na primeira fase da agenda de pesquisas sobre participação, acredita-se também que não se deve ignorar a importância dessas experiências participativas que estão ocorrendo no Brasil, diante de um contexto de globalização em que, de modo geral, os Estados nacionais se veem perdendo poder. Há que ressaltar a importância de a participação estar presente no projeto de governo que está no poder e da vontade política de promover a participação, ainda mais porque isso promove a mobilização de uma agenda de estudos para analisar e criticar as experiências práticas, apontando para mudanças mais significativas no futuro.

Percebe-se, contudo, que a participação não foi o método central do governo, não se destacou ao ponto de se tornar um estilo marcante da atuação política e de gestão das políticas públicas nas diferentes esferas de poder e nas diversas áreas de governo. Houve avanços, houve ampliação da participação quantitativa e qualitativamente, houve a consecução de algumas demandas, que inclusive se tornaram importantes programas de governo, ainda que as demandas, as sugestões, as propostas e as resoluções sejam muito amplas e a maioria não tenha tido execução. Percebe-se também a falta de interface entre as diferentes áreas e temas, não apenas do governo com a sociedade, mas internamente nos IPs e entre os órgãos, evitando que haja mais disputa de recursos do que uma cooperação e coordenação de programas.

Enfim, mais uma vez, é necessário ressaltar a importância das experiências e da agenda de pesquisa, com um papel crítico para impulsionar qualitativamente os resultados da participação social no Brasil, que apesar de ser um bom exemplo, está muito aquém do que já existe de acúmulo teórico. Há, no entanto, um déficit muito grande no aspecto deliberativo e no controle social sobre as políticas públicas, assim como existe um grande desafio de potencializar e articular as experiências de democracia participativa nos âmbitos locais com os mecanismos de participação no âmbito federativo.

\section{BIBLIOGRAFIA}

ABERS, R.N. e KECK, M.E. Representando a diversidade: Estado, sociedade e "relações fecundas" nos conselhos gestores. CADERNO CRH, Salvador, v. 21, n. 52, p. 99-112, Jan./Abr. 2008;

ALMEIDA, D.C.R e CUNHA, E.S.M. A análise da deliberação democrática: princípios, conceitos e variáveis relevantes (p. 109-124). In: PIRES, R.R.C.(org) Efetividade das instituições participativas no Brasil: estratégias de avaliação. Brasília: Ipea, 2011;

BORBA, J. Participação política como resultado das instituições participativas: oportunidades políticas e o perfil da participação (P.65-76). In: PIRES, R.R.C.(org) Efetividade das instituições participativas no Brasil: estratégias de avaliação. Brasília: Ipea, 2011; 
BRASIL (2011). Org. DULCI, L. Democracia Participativa, nova relação do Estado com a sociedade (2003-2010). Brasília: Secretaria Geral da Presidência da República, 2011;

CAMPOS, G.A.G., Participação e representações não avaliativas: a produção de significados nas experiências participativas (p. 53-65). In: PIRES, R.R.C.(org) Efetividade das instituições participativas no Brasil: estratégias de avaliação. Brasília: Ipea, 2011;

CORTES, S.V. e SILVA, M. K. Sociedade civil, instituiçôes e atores estatais: interdependências e condicionantes da atuação de atores sociais em fóruns participativos. Revista Estudos Sociológicos. Araraquara (SP), v.15, n.29, p.425-444, 2010;

CORTES, S.V. Instituições participativas e acesso a serviços públicos nos municípios brasileiros (p. 77-84). In: PIRES, R.R.C.(org) Efetividade das instituições participativas no Brasil: estratégias de avaliação. Brasília: Ipea, 2011;

CUNHA, E.S.M., ALMEIDA, D.C.R., FARIA, C.F. e RIBEIRO, U.C. Uma estratégia multidimensional de avaliação dos conselhos de políticas: dinâmica deliberativa, desenho institucional e fatores exógenos (p.297-321). In PIRES, R.R.C.(org) Efetividade das instituições participativas no Brasil: estratégias de avaliação. Brasília: Ipea, 2011;

DAGNINO, E.; OLIVEIRA, A.J.; PANFICHI, A. Para uma outra leitura da disputa pela construção democrática na América latina. In: DAGNINO, E.; OLIVEIRA, A.J.; PANFICHI, A. (orgs) A disputa pela construção democrática na América Latina. SP: Paz e Terra; Campinas: Unicamp, 2006;

ELSTUB, S. Overcoming complexity: institutionalising deliberative democracy through secondary associations. The Good Society, V. 16, N. 1, 2007, pp. 14-22;

FARIA, C.F e RIBEIRO, U.C. Desenho institucional: variáveis relevantes e seus efeitos sobre o processo participativo (p.125- 136). In: PIRES, R.R.C.(org) Efetividade das instituições participativas no Brasil: estratégias de avaliação. Brasília: Ipea, 2011;

FONSECA, I.F. Relações de poder e especificidades do contexto em fóruns participativos (159-170). In: PIRES, R.R.C.(org) Efetividade das instituições participativas no Brasil: estratégias de avaliação. Brasília: Ipea, 2011;

IPEA (2012). Participação social como método de governo: um mapeamento das "interfaces socioestatais" nos programas federais. Brasília: Comunicado no 132 do IPEA (29p), 25 de janeiro de 2012;

LAVALLE, A.G., Participação: valor, utilidade, efeitos e causas (p.33-42). In: PIRES, R.R.C.(org) Efetividade das instituições participativas no Brasil: estratégias de avaliação. Brasília: Ipea, 2011;

LUBAMBO, Catia W. ; MIRANDA, A. P. . O que há de novo na análise da participação depois de duas décadas?. In: Sylvana Maria Brandão Aguiar (org.). (Org.). Gestão Pública: práticas e desafios. 1 ed. Recife: Bagaço, 2007, v. 1, p. 15-50;

LUCHMANN, L. A representação no interior das experiências de participação. Revista Lua Nova. nº 70. São Paulo: 2007;

LÜCHMANN, L. H.H. Modelos contemporâneos de democracia e o papel das associações. (mimeo). Florianópolis: UFSC, 2011;

SILVA, F.S. "De cada um conforme suas capacidades": participação, ambientes institucionais e capacidade de incidência em políticas públicas (p.187-196). In: PIRES, R.R.C.(org) Efetividade das instituições participativas no Brasil: estratégias de avaliação. Brasília: Ipea, 2011;

SOUZA, C.H.L. Conferências e os desafios metodológicos de seu estudo (p. 197-209). In: PIRES, R.R.C.(org) Efetividade das instituições participativas no Brasil: estratégias de avaliação. Brasília: Ipea, 2011;

TATAGIBA, L.F. A questão dos atores, seus repertórios de ação e implicações para o processo participativo (p. 171- 186). In: PIRES, R.R.C.(org) Efetividade das instituições participativas no Brasil: estratégias de avaliação. Brasília: Ipea, 2011;

WAMPLER, B. (a) Instituições participativas como "enxerto" na estrutura do Estado: a importância de contextos, atores e suas estratégias (p. 152-171). In: PIRES, R.R.C.(org) Efetividade das instituições participativas no Brasil: estratégias de avaliação. Brasília: Ipea, 2011;

WAMPLER, B. (b) Que tipos de resultados devemos esperar das instituições participativas? (p.41-51). In: PIRES, R.R.C.(org) Efetividade das instituições participativas no Brasil: estratégias de avaliação. Brasília: Ipea, 2011; 
José Roberto Paludo. Abordagem sobre a participação no Governo Lula

YOUNG, I.M. Activist challenges to deliberative democracy. Political Theory, vol. 29, n. 5, 2001, p. 670-690;

CC BY-NC-ND 